\title{
Estimativas de Índices de Vegetação na Microbacia do Rio Puruzinho, Sul do Amazonas
}

\section{Estimates of Vegetation Indexes in the Microbacia of Puruzinho River, South of Amazonas}

\author{
Uilson Franciscon \\ Mestre em Ciências Ambientais- Universidade Federal do Amazonas \\ uilsonfranciscon@gmail.com \\ José Maurício da Cunha \\ Doutor em Física Ambiental - Universidade Federal do Amazonas \\ maujmc@gmail.com \\ Milton César Costa Campos \\ Doutor em Ciência do Solo - Universidade Federal da Paraíba \\ mcesarsolos@gmail.com
}

Douglas Marcelo Pinheiro da Silva Doutor em Horticulta - Universidade Federal do Amazonas dougllasmarcelo@gmail.com

Natasha Souza Araújo Lemos

Mestranda em Ciências Ambientais - Universidade Federal do Amazonas

lemos.natasha1@gmail.com

Elilson Gomes de Brito Filho

Graduando em Agronomia - Universidade Federal da Paraíba

bfsambiente@gmail.com

Wildson Benedito Mendes Brito

Mestre em Agronomia Tropical - Universidade Federal do Amazonas

wild.brito@gmail.com

\section{Resumo}

A Amazônia é o maior bioma do Brasil, abrange as bacias hidrográficas do rio Amazonas, AraguaiaTocantins, bacias costeiras do Norte Ocidental e bacias costeiras do Nordeste. A microbacia do Rio Puruzinho, está inserida em uma região onde há ocorrência exclusiva dos chamados Campos Naturais. Assim, este trabalho teve como objetivo geral analisar a dinâmica espaço temporal dos índices de vegetação na detecção de transformações ambientais em uma microbacia hidrográfica do rio Puruzinho. A área de estudo localiza-se em Humaitá, AM. A bacia do rio Puruzinho situa-se no interflúvio Purus-Madeira, Sudoeste da Amazônia Brasileira. Para o cálculo da estimativa dos Índices de vegetação e biofísicos, foi utilizado a ferramenta Model Maker do software ERDAS Imagine 2014. A maior média do NDVI foi para a imagem do ano de 2010, apresentando valor médio de 0,354 e a menor média do NDVI foi para o ano de 2017. O resultado do desvio padrão do NDVI apresentou altos valores, variando entre 0,278 para a imagem do ano de 2017 e 0,358 para o ano de 2010. Há uma predominância na ocorrência da classe representada pela cor verde clara, para os anos 2006, 2008, 2011 e 2017, revelando uma predominância na ocorrência de vegetação menos densa para esses anos. Os índices biofísicos exibiram padrão inverso entre as áreas de floresta densa e áreas antropizadas. A utilização dos índices biofísicos, combinados com técnicas de sensoriamento remoto 
e geoprocessamento, mostraram-se ferramenta imprescindível no monitoramento e detecção de áreas com transformações ambientais.

Palavras-chave: Amazônia; Bacia Hidrográfica; Sensoriamento remoto.

\begin{abstract}
The Amazon is the largest biome in Brazil, covering the hydrographic basins of the Amazon River, Araguaia-Tocantins, coastal basins in the North West and coastal basins in the Northeast. The Puruzinho River microbasin is inserted in a region where there is an exclusive occurrence of the socalled Natural Fields. Thus, this work had as a general objective to analyze the dynamic space-time of the vegetation indices in the detection of environmental transformations in a watershed of the Puruzinho River. The study area is located in Humaitá, AM. The Puruzinho River basin is located in the Purus-Madeira interfluvium, Southwest of the Brazilian Amazon. To calculate the estimate of the Indices of vegetation and biophysicists, the Model Maker tool of the ERDAS Imagine 2014 software was used. The highest average of the NDVI was for the image of the year 2010, presenting an average value of 0.354 and the lowest average of the NDVI was for the year 2017. The result of the standard deviation of the NDVI presented high values, varying between 0.278 for the image for the year 2017 and 0.358 for the year 2010. There is a predominance in the occurrence of the class represented by the light green color, for the years 2006, 2008, 2011 and 2017, revealing a predominance in the occurrence of less dense vegetation for those years. The biophysical indices showed an inverse pattern between the areas of dense forest and anthropized areas. The use of biophysical indexes, combined with remote sensing and geoprocessing techniques, proved to be an essential tool in the monitoring and detection of areas with environmental changes.
\end{abstract}

Keywords: Amazonian; Hydrographic Basin; Remote Sensing.

\title{
1. INTRODUÇÃO
}

A Amazônia ocupa uma área de $4,19.10^{6} \mathrm{~km}^{2}$ e é o maior bioma do Brasil. Abrange as bacias hidrográficas do rio Amazonas e Araguaia-Tocantins e as bacias costeiras do Norte Ocidental e do Nordeste. No decorrer dos anos, a região vem sendo alvo de exploração desordenada, com o desmatamento avançando em um ritmo alarmante, até 2004, o desmatamento havia atingido cerca de $6,3 \%$ do território das áreas protegidas, dez reservas já haviam perdido mais de $20 \%$ da floresta original (ROSSONI e MORAES, 2017). Assim, o bioma vem sofrendo impactos em sua cobertura vegetal, causado por atividades antrópicas caracterizados por práticas como grilagem de terras, extração ilegal de madeira e transformação de imensas áreas de floresta em pastagens (FEARNSIDE, 2006; SOUZA FILHO et al., 2006).

Devido a extensão geográfica, diversidade e complexidade de seu ecossistema, as técnicas de sensoriamento remoto surgem como uma importante ferramenta para o monitoramento ambiental na Amazônia. O estudo da dinâmica da vegetação e das transformações ambientais é possível a partir de dados provenientes dos sensores orbitais, cujas refletâncias de superfície distribuídas em diferentes bandas espectrais resultam em produtos que podem ser combinados para avaliação das variáveis biofísicas (JÚNIOR et al., 2020). 
A vegetação possui padrões de reflectância e a partir da observação do comportamento espectral dos alvos é possível a sua diferenciação quando comparados a outros materiais, diante da interação de diferentes bandas e seus registros em diferentes intervalos de comprimento de onda. Assim, com a refletância dos alvos vegetais é possível estimar alguns índices de vegetação como o IAF (Índice de Área Foliar), o NDVI (Índice de Vegetação da Diferença Normalizada) e o SAVI (Índice de Vegetação Ajustado ao Solo), classificando a vegetação e gerando mapas temáticos de uso e cobertura do solo dos ambientes (MORAES, 2002).

A partir do estudo dos índices biofísicos em uma serie temporal é possível avaliar as alterações ocorridas na superfície da Terra. O NDVI (cujos valores oscilam entre -1 e +1 ) nos permite identificar e caracterizar a presença de superfície verde e sua distribuição espacial, as quais podem estar associadas às ações antrópicas ou simplesmente por variações climáticas naturais, que regem os ciclos fenológicos da vegetação (QUESADA et al., 2017).

O NDVI e o albedo estão intimamente relacionados, tendo uma relação inversa: regiões de elevada vegetação e com alta densidade o NDVI tende a ser positivo e próximo de um e o albedo tende a ser baixo e próximo de zero; onde se tem pouca vegetação ou baixa densidade, com predomínio de solos expostos, úmidos ou espelhos d'agua, o NDVI tende a ser negativo e próximo de -1 e o albedo tende a ser alto, distante de zero e mais próximo de um. O albedo caracteriza-se pela capacidade dos alvos em refletir a radiação incidente sobre ele, sendo junto com o NDVI, um importante indicador em estudos ambientais (LEITE et al., 2019).

A microbacia do Rio Puruzinho insere-se em uma região onde há ocorrência exclusiva dos chamados Campos Naturais. Este é um ambiente com características peculiares e já passou por intensas transformações antrópicas por localizar-se na zona denominada Arco do Desmatamento. Esta zona é uma área sob intensa pressão de transformações ambientais representando uma fronteira agrícola, que abrange o oeste e noroeste do Maranhão; o leste, sul e parte do oeste do Pará; o oeste e norte do Tocantins; o leste, centro-oeste e norte do Mato Grosso, todo o estado de Rondônia e do Acre e o sul do Amazonas.

Há muita discussão em âmbito nacional e internacional acerca das mudanças ambientais ocasionadas por ações antrópicas sobre a superfície terrestre, as quais contribuem para as mudanças climáticas, interações entre os sistemas da atmosfera, da superfície terrestre e seus impactos ambientais provocados a partir destas transformações.

Consideração a grande utilidade das ferramentas georreferenciadas para estudos ambientais, o presente trabalho objetiva estimar e analisar a dinâmica espaço-temporal dos índices de vegetação (NDVI, SAVI e IAF), da temperatura da superfície e albedo, visando a detecção de transformações ambientais na microbracia hidrográfica do Rio Puruzinho, por meio de imagens capturadas pelos satélites Landsat 5 e 8 nos anos de 2006, 2008, 2010, 2011, 2015 e 2017. 


\section{METODOLOGIA}

A área de estudo localiza-se no município de Humaitá/AM, situado ao Sul do Estado do Amazonas. A bacia do rio Puruzinho encontra-se no interflúvio Purus-Madeira, Sudoeste da Amazônia Brasileira (Figura 1).

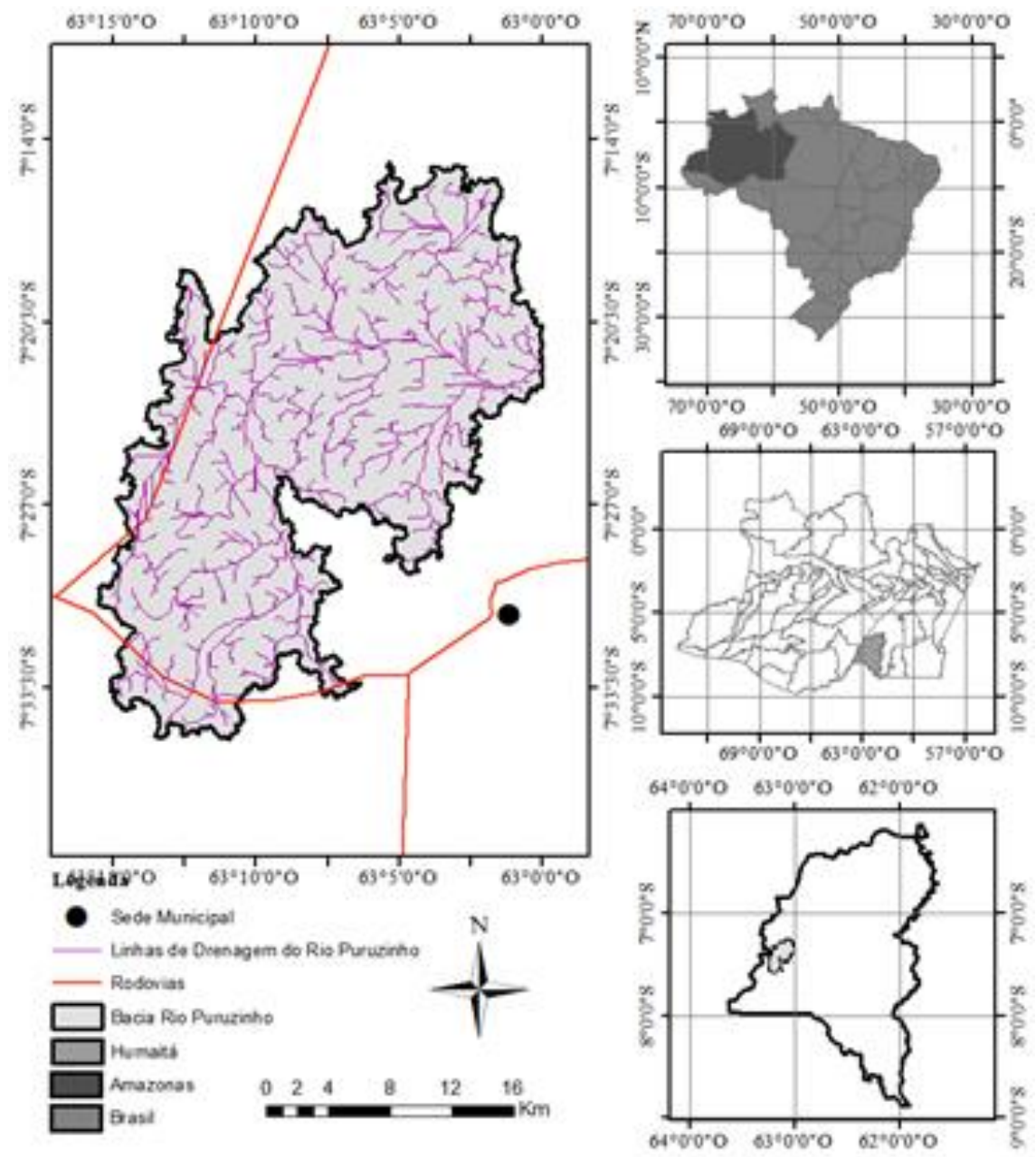

Figura 1 - Localização da bacia do Rio Puruzinho, Humaitá/AM.

O clima da região, segundo a classificação de Köppen pertence ao grupo A (Clima Tropical Chuvoso) do tipo climático Am (chuvas do tipo monção), apresentando um período seco de curta duração. A pluviosidade está limitada pelas isoietas de 2.250 e $2.750 \mathrm{~mm}$, com período chuvoso iniciando em outubro e prolongando-se até junho. As temperaturas médias anuais variam entre $25^{\circ} \mathrm{C}$ e $27^{\circ} \mathrm{C}$ e a umidade relativa do ar fica entre 85 e $90 \%$ (ALVAREZ et al., 2014).

A delimitação da área da bacia foi feita com base na imagem do SRTM (Shuttle Radar Topography Mission), que tem resolução espacial de 90 metros (FARR et al., 2007). Os limites da bacia foram determinados pelos padrões de drenagem e divisores de águas topográficos utilizando-se o software ArcGIS versão 10.3, através da extensão ArcHydro, selecionando um DEM (Digital Elevation Model) obtido a partir das imagens SRTM. 
As imagens utilizadas neste estudo foram obtidas pelos sensores TM (Thematic Mapper) do satélite Landsat 5 e OLI/TIRS (Operational Land Imager/Thermal Infrared Sensor) do satélite Landsat 8, disponibilizadas pelo Instituto Nacional de Pesquisas Espaciais (INPE). Foram recortadas as cenas conforme a área de estudo, entre os anos de 2006 a 2017, na mesma época do ano, em dias próximos para todos os anos na Tabela 1.

Tabela 1: Dados das imagens capturadas pelos satélites Landsat 5 e Landsat 8.

\begin{tabular}{cccccc}
\hline Data da imagem & Órbita/ponto & Satélite & DSA & Hora da passagem & E $\left(^{\mathbf{0}}\right)$ \\
\hline $23 / 07 / 2006$ & $232 / 65$ & Landsat 5 & 204 & $14: 13: 26$ & 49,2194 \\
$28 / 07 / 2008$ & $232 / 65$ & Landsat 5 & 209 & $14: 06: 31$ & 48,7243 \\
$02 / 07 / 2010$ & $232 / 65$ & Landsat 5 & 183 & $14: 10: 51$ & 47,3334 \\
$06 / 08 / 2011$ & $232 / 65$ & Landsat 5 & 218 & $14: 08: 59$ & 50,5110 \\
$01 / 08 / 2015$ & $232 / 65$ & Landsat 8 & 213 & $14: 19: 56$ & 51,3799 \\
$06 / 08 / 2017$ & $232 / 65$ & Landsat 8 & 218 & $14: 20: 18$ & 52,4322 \\
\hline
\end{tabular}

$\mathrm{DSA}=$ dia sequencial do ano; $\mathrm{E}$ = ângulo de elevação do sol.

No Mapeador Temático (TM) Landsat 5 as imagens são compostas por sete bandas espectrais cujas características estão contidas na Tabela 2.

Tabela 2: Descrição das bandas do Mapeador Temático (TM) do Landsat 5, com os correspondentes intervalos de comprimento de onda, coeficientes de calibração (radiância mínima - a e máxima - b) e irradiâncias espectrais.

\begin{tabular}{|c|c|c|c|c|c|}
\hline \multirow[t]{2}{*}{ Bandas } & \multirow[t]{2}{*}{$\begin{array}{l}\text { Comprimento } \\
\text { de Onda }(\mu \mathrm{m})\end{array}$} & \multirow[t]{2}{*}{$\begin{array}{c}\text { Resolução } \\
\text { Espacial (m) }\end{array}$} & \multicolumn{2}{|c|}{$\begin{array}{c}\text { Coeficientes de } \\
\text { Calibração }(W \mathrm{~m}-2 \text { sr- } \\
\mathbf{1} \mu \mathrm{m})\end{array}$} & \multirow{2}{*}{$\begin{array}{l}\text { Irradiância Espectral } \\
\text { no Topo da Atmosfera } \\
(\mathrm{Wm}-2 \mu \mathrm{m}-1)\end{array}$} \\
\hline & & & $\mathbf{A}$ & B & \\
\hline 1 (azul) & $0,45-0,52$ & 30 & $-1,52$ & 193 & 1957 \\
\hline 2 (verde) & $0,52-0,60$ & 30 & $-2,84$ & 365 & 1826 \\
\hline 3 (vermelho) & $0,63-0,69$ & 30 & $-1,17$ & 264 & 1554 \\
\hline 4 (IV-próximo) & $0,76-0,79$ & 30 & $-1,51$ & 221 & 1036 \\
\hline 5 (IV-médio) & $1,55-1,75$ & 30 & $-0,37$ & 30,2 & 215 \\
\hline 6 (IV-termal) & $10,4-12,5$ & 120 & 1,2378 & 15,303 & - \\
\hline 7 (IV-médio) & $2,08-2,35$ & 30 & $-0,15$ & 16,5 & 80,67 \\
\hline
\end{tabular}

Fonte: Chander e Markham (2003) e Allen et al., (2002).

Na Tabela 2 acima também estão incluídas a irradiância solar monocromática $\left(\mathrm{K}_{\lambda_{\mathrm{i}}}\right)$ das bandas reflectivas (bandas 1, 2, 3, 4, 5 e 7), incidente sobre uma superfície normal à direção dos raios solares no topo da atmosfera terrestre. O sensor TM mede a radiância espectral dos alvos e armazenaos na forma de níveis de cinza ou número digital (ND), cujos valores variam de 0 a 255 (8 bits), apresentando resolução espacial de 30m, exceto na banda termal (banda 6) com resolução de 120m.

No Operational Land Imager (OLI) e Thermal Infrared Sensor (TIRS) do satélite Landsat 8, cada imagem OLI é composta de nove bandas espectrais (bandas um a nove) e o TIRS possui duas 
bandas espectrais (bandas 10 e 11), cujas principais características estão representadas na Tabela 3.

Tabela 3: Descrição dos coeficientes de calibração do OLI - Landsat 8 e características das bandas espectrais.

\begin{tabular}{|c|c|c|c|c|}
\hline \multirow{2}{*}{ Bandas } & \multirow{2}{*}{$\begin{array}{c}\text { Comprimento de } \\
\text { Onda } \\
(\mu \mathrm{m})\end{array}$} & \multirow{2}{*}{$\begin{array}{l}\mathbf{R} \mathbf{E} \\
(\mathbf{m})\end{array}$} & \multicolumn{2}{|c|}{ Coeficientes de Calibração de Reflectância } \\
\hline & & & Fator multiplicativo $\left(\mathbf{m}_{\rho}\right)$ & $\begin{array}{c}\text { Fator } \\
\text { Aditivo }\left(\mathbf{A}_{\boldsymbol{\rho}}\right)\end{array}$ \\
\hline 1 OLI - Costal aerossol & $0,43-0,45$ & 30 & 0,00002 & $-0,1$ \\
\hline $2 \mathrm{OLI}-\mathrm{Azul}$ & $0,45-0,51$ & 30 & 0,00002 & $-0,1$ \\
\hline 3 OLI - Visível Verde & $0,53-0,59$ & 30 & 0,00002 & $-0,1$ \\
\hline 4 OLI - Visível Vermelho & $0,64-0,67$ & 30 & 0,00002 & $-0,1$ \\
\hline 5 OLI - IV Próximo & $0,85-0,88$ & 30 & 0,00002 & $-0,1$ \\
\hline 6 OLI - IV Médio (SWIR) 1 & $1,57-1,65$ & 30 & 0,00002 & $-0,1$ \\
\hline 7 OLI - IV Médio (SWIR) 2 & $2,11-2,29$ & 30 & 0,00002 & $-0,1$ \\
\hline 8 OLI - Pancromática & $0,50-0,68$ & 15 & 0,00002 & $-0,1$ \\
\hline 9 OLI - Cirrus & $1,36-1,38$ & 30 & 0,00002 & $-0,1$ \\
\hline 10 TIRS-IV térmico (TIRS)1 & $10,60-11,19$ & 30 & - & - \\
\hline 11 TIRS-IV térmico (TIRS)2 & $11,50-12,51$ & 30 & - & - \\
\hline
\end{tabular}

$\mathrm{IV}=$ Infravermelho; RE= Resolução Espacial;

Fonte: USGS, 2017.

A resolução espacial das imagens OLI é de 30m, exceto a banda pancromática (banda 8) com 15m. As bandas 10 e 11 relativas ao sensor TIRS possuem resolução de 100m mas são disponibilizadas com 30m. Todas as imagens OLI/TIRS possuem resolução espectral de 12 bits, mas são disponibilizadas em 16 bits, o que significa que a intensidade de cada pixel varia entre 0 a 65.535 , assegurando um maior nível de informação das áreas imageadas (FREIRES et al., 2020).

Para o cálculo da estimativa dos Índices de vegetação e biofísicos foi utilizado a ferramenta Model Maker do software ERDAS Imagine 2014, onde foi feito o processamento da imagens e estimativas a partir de modelos subsequentes nas etapas: radiância espectral; reflectância monocromática; albedo no topo da atmosfera; albedo da superfície; índices de vegetação NDVI, SAVI e IAF; emissividades; temperatura da superfície.

Para as imagens do Landsat 5 , no cômputo da irradiância solar monocromática $\left(\mathrm{K}_{\lambda \mathrm{i}}\right)$ foi realizada a Calibração Radiométrica, em que o número digital (ND) de cada pixel da imagem é convertido em radiância espectral monocromática. Essas radiâncias representam a energia solar refletida por cada pixel, por unidade de área, de tempo, de ângulo sólido e de comprimento de onda, medida no nível do satélite Landsat $5(705 \mathrm{Km})$, para as bandas 1, 2, 3, 4, 5 e 7 . Para a banda 6, a radiância representa a energia emitida por cada pixel. A obtenção da radiância de cada banda é feita segundo a equação de Markham e Baker (1987): 


$$
\mathrm{L}_{\lambda \mathrm{i}}=\mathrm{a}_{\mathrm{i}}+\left(\frac{\mathrm{b}_{\mathrm{i}}-\mathrm{a}_{\mathrm{i}}}{255}\right) \mathrm{ND},
$$

Onde:

$\mathrm{L}_{\lambda \mathrm{i}}=$ radiância espectral monocromática, a e b são as radiâncias espectrais mínimas e máximas $\left(\mathrm{Wm}^{-2} \mathrm{sr}^{-1} \mu \mathrm{m}^{-1}\right)$ conforme a Tabela 1 ;

$\mathrm{ND}=$ intensidade do pixel (número digital - número inteiro de 0 a 255);

$\mathrm{i}=$ bandas 1, 2, 3, 4, 5, 6 e 7 do satélite Landsat 5 .

Para as imagens do Landsat 8, a conversão de níveis de cinza da imagem para radiância foi feita usando os fatores de redimensionamento fornecidos no arquivo de metadados da imagem, conforme a equação (USGS, 2014):

$\mathrm{L}_{\lambda}=\mathrm{M}_{\mathrm{L}} \cdot Q_{c a l}+\mathrm{A}_{\mathrm{L}}$

Onde:

$\mathrm{L}_{\lambda}=$ radiância espectral no topo da atmosfera;

$\mathrm{M}_{\mathrm{L}}=$ Fator de redimensionamento multiplicativo específico da banda;

$\mathrm{A}_{\mathrm{L}}=$ Fator de redimensionamento aditivo específico da banda;

$\mathrm{Q}_{\mathrm{cal}}=$ Valores de pixel de produto padrão (DN) quantizados e calibrados.

Para as imagens do Landsat 5, o cômputo da reflectância monocromática de cada banda ( $\left.\rho_{\lambda \mathrm{i}}\right)$, definida como sendo a razão entre o fluxo de radiação solar refletida e o fluxo de radiação solar incidente é obtida segundo a equação proposta por Allen et al., (2002).

Quando a área de estudo tem pequena, ou mesmo, declividade nula, o cosseno do ângulo de incidência da radiação solar é simplesmente obtido a partir do ângulo de elevação do Sol - E, que se encontra no cabeçalho da imagem Landsat, em que o argumento do cosseno está em radiano.

Para as imagens do Landsat 8, a conversão de níveis de cinza da imagem para refletância foi feita usando coeficientes de reescalonamento fornecidos no arquivo de metadados na imagem utilizando a equação, conforme USGS (2014).

Para o Landsat 5 , o cômputo do albedo planetário $\left(\alpha_{\text {toa }}\right)$, isto é, o albedo não ajustado a transmissividade atmosférica, é obtido pela combinação linear das reflectâncias monocromáticas.

Para o Landsat 8, o albedo no topo da atmosfera é obtido pela combinação linear das refletâncias espectrais $\rho_{\lambda, b}$, com seu respectivos pesos $\varpi_{\lambda, b}$, estabelecido para cada banda.

O NDVI é obtido através da razão entre a diferença das refletividades do Infravermelho (IV) próximo ( $\boldsymbol{\rho}_{\mathbf{I V}}$ ) e do vermelho ( $\boldsymbol{\rho}_{\mathbf{v}}$ ), pela soma das mesmas: 
$\mathrm{NDVI}=\frac{\rho_{\mathrm{IV}}-\rho_{\mathrm{V}}}{\rho_{\mathrm{IV}}+\rho_{\mathrm{V}}}$

Para o cálculo do SAVI tem sido utilizada a expressão (HUETE, 1988):

$$
\text { SAVI }=\frac{(1+\mathrm{L})\left(\rho_{\mathrm{IV}}-\rho_{\mathrm{V}}\right)}{\left(\mathrm{L}+\rho_{\mathrm{IV}}+\rho_{\mathrm{V}}\right)}
$$

Onde:

$\mathrm{L}=$ função do tipo de solo. Em estudo recente utilizamos $\mathrm{L}=0$, 1 , embora o seu valor mais frequente seja L = 0,5 (HUETE \&WARRICK, 1990; ACCIOLY et al., 2002; BOEGH et al., 2002).

O IAF é definido pela razão entre a área foliar de toda a vegetação por unidade de área utilizada por essa vegetação. O IAF é um indicador da biomassa de cada pixel da imagem e o mesmo foi computado pela seguinte equação empírica obtida por Allen et al., (2002):

$$
\mathrm{IAF}=-\frac{\ln \left(\frac{0,69-\mathrm{SAVI}}{0,59}\right)}{0,91}
$$

Para a obtenção da temperatura da superfície, é utilizada a equação de Planck invertida, válida para um corpo negro. Como cada pixel não emite radiação eletromagnética como um corpo negro, há a necessidade de introduzir a emissividade de cada pixel no domínio espectral da banda termal $\varepsilon_{\mathrm{NB}}$, qual seja: $10,4-12,5 \mu \mathrm{m}$. Por sua vez, quando do cômputo da radiação de onda longa emitida por cada pixel, há de ser considerada a emissividade no domínio da banda larga $\varepsilon_{0}(5-100$ $\mu \mathrm{m})$. Segundo Allen et al., (2002), as emissividades $\varepsilon_{\mathrm{NB}} \mathrm{e}^{\varepsilon_{\mathrm{o}}}$ podem ser obtidas para NDVI $>0 \mathrm{e}$ IAF $<3$, segundo:

$$
\begin{aligned}
& \varepsilon_{\mathrm{NB}}=0,97+0,0033 \mathrm{IAF} \\
& \varepsilon_{0}=0,95+0,01 . \mathrm{IAF}
\end{aligned}
$$

Para pixels com $\mathrm{IAF} \geq 3, \varepsilon_{\mathrm{NB}}=\varepsilon_{0}=0,98$ e para corpos de água $(\mathrm{NDVI}<0) \varepsilon_{\mathrm{NB}}=0,99 \mathrm{e}$ $\varepsilon_{0}=0,985$, conforme recomendações de Allen et al., (2002).

Para o Landsat 5, a obtenção da temperatura da superfície foi utilizada a radiância espectral da banda termal $\mathbf{L}_{\lambda, 6}$ e a emissividade $\varepsilon_{\mathrm{NB}}$ obtida na etapa anterior. Dessa forma, obtém-se a temperatura da superfície $\left(\mathrm{T}_{\mathrm{s}}\right)$ pela seguinte expressão:

$$
\mathrm{T}_{\mathrm{s}}=\frac{\mathrm{K}_{2}}{\ln \left(\frac{\varepsilon_{\mathrm{NB}} \mathrm{K}_{1}}{\mathrm{~L}_{\lambda, 6}}+1\right)}
$$


Onde:

$\mathrm{K}_{1}=607,76 \mathrm{Wm}^{-2} \mathrm{sr}^{-1} \mu \mathrm{m}^{-1}$ e $\mathrm{K}_{2}=1260,56 \mathrm{~K}$ são constantes de calibração da banda termal do Landsat 5 (ALLEN et al., 2002).

Para o Landsat 8, a obtenção da temperatura da superfície $\left(\mathrm{T}_{\mathrm{s}}\right)$ foi utilizada a radiância espectral da banda termal $\mathrm{L}_{\lambda, 10}$, usando as constantes térmicas fornecidas no arquivo de metadados, pela equação (USGS, 2014):

$\mathrm{T}_{\mathrm{S}}=\frac{\mathrm{K}_{2}}{\ln \left(\frac{\mathrm{K} 1}{\mathrm{~L}_{2}}\right)+1}$

Onde:

$\mathbf{T}_{\mathrm{s}}=$ temperatura da superfície;

$\mathrm{L}_{\lambda}=$ Radiância espectral no topo da atmosfera;

$\mathrm{K}_{1}=$ Constante de conversão térmica específica da banda dos metadados;

$\mathrm{K}_{2}=$ Constante de conversão térmica específica da banda dos metadados.

Após a obtenção dos resultados foram realizadas análises estatísticas com o uso da Estatística Descritiva. Foram calculados média, mínimo, máximo e desvio padrão entre os pixels para cada ano estudado na bacia, utilizando a fórmula do desvio padrão populacional. Para a análise da dinâmica espaço temporal foi calculado o desvio padrão entre os pixels na mesma posição geográfica, utilizando a fórmula do desvio padrão amostral, para calcular o desvio padrão entre os pixels nos 6 anos estudados.

\section{RESULTADOS E DISCUSSÃO}

Os resultados do NDVI em relação aos anos entre 2006 e 2017 são apresentados na Tabela 5. Em estudos na bacia do rio Bacanga, Silva et al., (2016) encontraram um valor pouco maior, de 0,420 para o ano de 2010, em estudos de mapeamento e comparação entre índices de vegetação utilizando imagem OLI/Landsat 8. Enquanto Borges et al., (2010) encontraram valores superiores a 0,50 em áreas de cultivo. De acordo com Borella et al., (2018), a disponibilidade hídrica proporcionada por irrigação ou pluviosidade resulta em maior vigor vegetal, ressaltando os valores de NDVI.

Tabela 4: Estatística descritiva do NDVI para a bacia do Rio Puruzinho.

\begin{tabular}{ccccccc}
\hline \multirow{2}{*}{ Estatística } & $\mathbf{2 0 0 6}$ & $\mathbf{2 0 0 8}$ & $\mathbf{2 0 1 0}$ & $\mathbf{2 0 1 1}$ & $\mathbf{2 0 1 5}$ & $\mathbf{2 0 1 7}$ \\
\hline Mínimo: & $-0,656$ & $-0,975$ & $-0,960$ & $-0,768$ & $-0,442$ & $-0,295$
\end{tabular}




\begin{tabular}{ccccccc}
\hline Máximo: & 0,802 & 0,823 & 0,847 & 0,810 & 0,826 & 0,767 \\
Média: & 0,351 & 0,339 & 0,354 & 0,321 & 0,285 & 0,276 \\
Desvio Padrão: & 0,291 & 0,317 & 0,358 & 0,336 & 0,307 & 0,278 \\
\hline
\end{tabular}

Os menores valores encontrados foram $-0,975$ e $-0,960$ para os anos de 2008 e 2010, respectivamente. Com relação aos valores mínimos de NDVI, os valores negativos indicam a incidência de áreas com presença de água, ocorrência de lagos, rios ou áreas parcialmente inundadas.

Já os maiores valores mensurados foram no ano de 2010, na ordem de 0,847 e no ano de 2015 na ordem de 0,826. Altos valores de NDVI indicam a ocorrência de vegetação mais densa e com maior vigor de desenvolvimento vegetal. Tais resultados corroboram com Silva et al., (2005), que encontraram valores de 0,750 e 0,780 para áreas com vegetação irrigada, nos anos de 2000 e 2001, respectivamente, e valores de -0,300 e -0,330 para lagos, em estudos sobre o balanço de radiação em áreas irrigadas nos Estados de Pernambuco e Bahia utilizando imagens Landsat 5 - TM. Segundo Borges et al., (2010), altos valores de NDVI indicam estágio avançado de desenvolvimento fenológico, com máxima cobertura do solo, enquanto baixos valores são compatíveis com área de solo exposto ou vegetação rala.

O resultado do desvio padrão do NDVI apresentou altos valores, variando entre 0,278 para a imagem do ano de 2017 e 0,358 para o ano de 2010. Esses altos valores de desvio padrão, podem ser explicados pelos diferentes tipos de ambientes na bacia, como florestas, vegetações menos densas, rios, lagos e áreas antropizadas. Paiva et al., (2016), estudando análise dos efeitos do déficit hídrico na resposta temporal do NDVI no Estado do Amazonas, concluíram que a variação do mesmo está relacionado diretamente com as variações na disponibilidade hídrica da região, tendo influência nas condições fenológicas da vegetação.

A representação dos valores de NDVI na Figura 2 para os anos de 2006, 2008, 2010, 2011, 2015 e 2017 foram apresentadas na forma de intervalos, divididas em cinco classes, a saber: com valores menores que zero; segunda classe entre 0 e 0,25 ; terceira classe entre 0,25 e 0,50; quarta classe entre 0,50 e 0,70 e última classe para valores de NDVI maior que 0,70 (MACEDO et al., 2016).

Há maior ocorrência da classe com valores de NDVI entre 0,50 e 0,70 para os anos 2006, 2008, 2011 e 2017, revelando uma predominância na ocorrência de vegetação menos densa para esses anos, por outro lado, para os anos de 2010 e 2015, a classe dominante foi de NDVI maior que 0,70, evidenciando a ocorrência da vegetação em um estado mais denso, corroborando com Silva et al., (2016) que encontraram resultados semelhantes. 

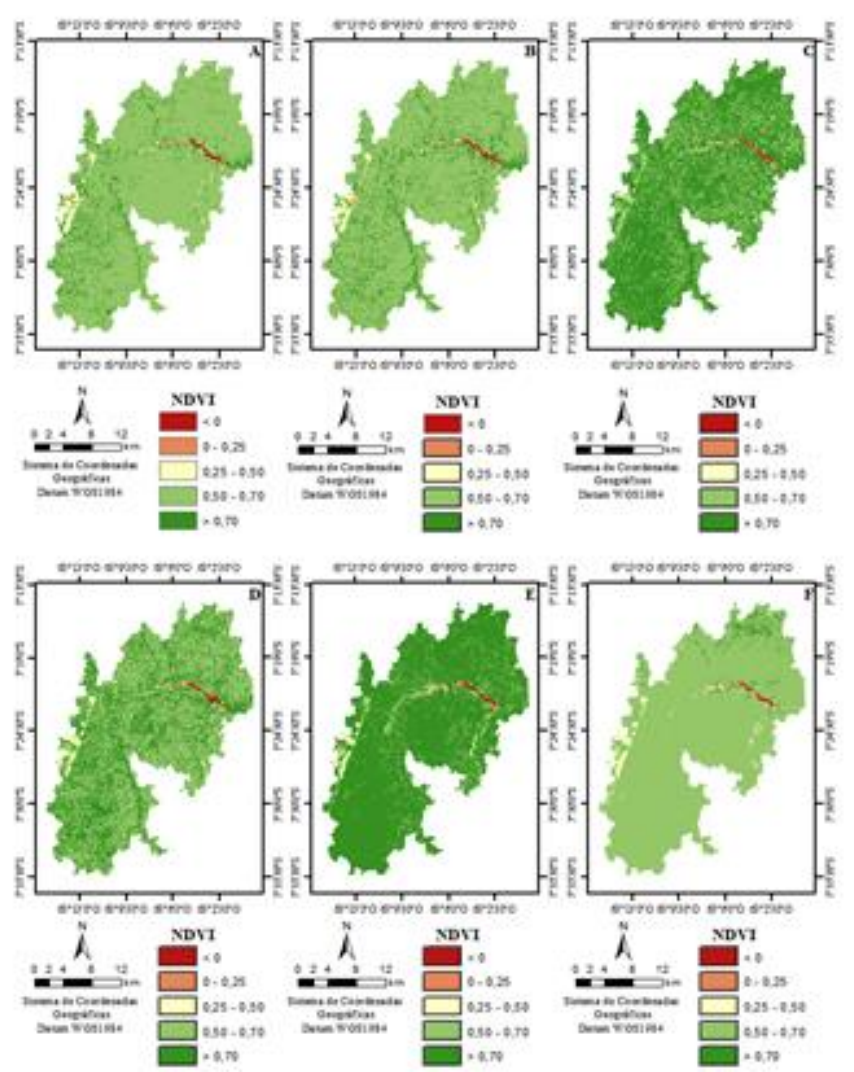

Figura 2 - Distribuição espacial do NDVI, para os anos de 2006 (A), 2008 (B), 2010 (C), 2011(D), 2015 (E) e 2017 (F), na bacia do Rio Puruzinho.

A representação da distribuição espaço temporal do desvio padrão médio dos anos estudados para o NDVI é apresentada na Figura 3. A distribuição do desvio padrão médio foi representada no mapa temático divididos em 5 intervalos, onde o primeiro intervalo representa desvios padrão menores que 0,02 ; o segundo, valores entre o desvio $0,02-0,04$; o terceiro, valores entre $0,04-0,06$; o quarto, valores entre $0,06-0,08$ e por fim, os desvios padrão maiores que 0,08 .

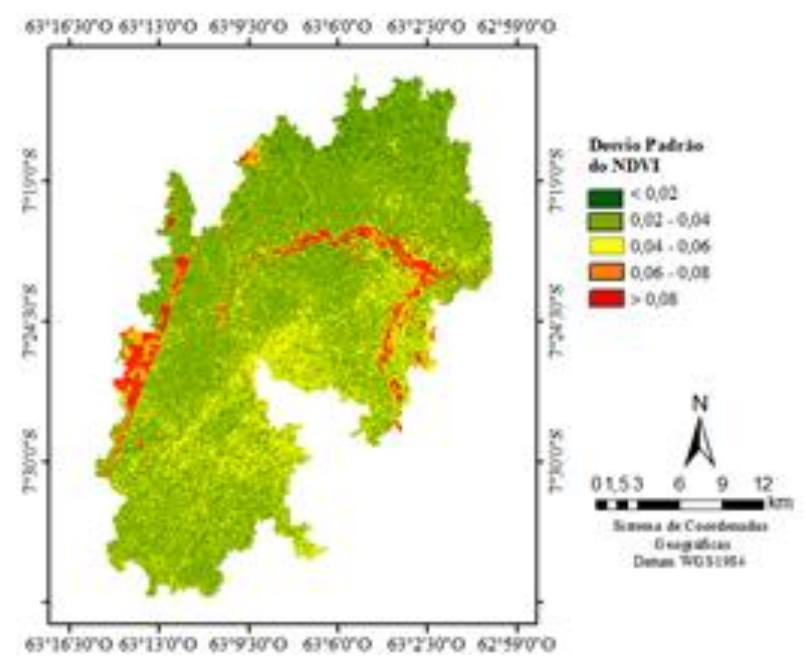

Figura 3 - Distribuição espaço temporal do desvio padrão médio para o NDVI, na bacia do rio Puruzinho.

Os maiores valores de desvio padrão - desvios maiores que 0,08 , mostram onde houve maior alteração dos valores de NDVI ao longo dos anos estudados. Na região central do mapa, há uma 
grande variação do NDVI, sendo atribuída a variação sazonal da profundidade do lago, situado nessa região.

Na parte oeste da bacia, ao longo da Br 319, temos outra região de grande variação do NDVI, área próximas a rodovia são áreas antropizadas ou que em estão em processo de antropização, o que justifica essa grande variação. Segundo Santos et al., (2015), o NDVI também é influenciado pela disponibilidade hídrica do ambiente, assim justificando a variação ao longo dos anos.

Os resultados das análises do SAVI entre os anos de 2006 a 2017 são apresentados na Tabela 6, com valores médios de SAVI variando entre o maior valor de 0,314 no ano de 2010 e o menor valor para o ano de 2017 , de 0,275 .

Tabela 5: Estatística descritiva do SAVI para a bacia do Rio Puruzinho.

\begin{tabular}{ccccccc}
\hline Estatística & $\mathbf{2 0 0 6}$ & $\mathbf{2 0 0 8}$ & $\mathbf{2 0 1 0}$ & $\mathbf{2 0 1 1}$ & $\mathbf{2 0 1 5}$ & $\mathbf{2 0 1 7}$ \\
\hline Mínimo: & $-0,294$ & $-0,471$ & $-0,356$ & $-0,375$ & $-0,204$ & $-0,168$ \\
Máximo: & 0,702 & 0,706 & 0,736 & 0,708 & 0,748 & 0,694 \\
Média: & 0,298 & 0,294 & 0,314 & 0,286 & 0,309 & 0,275 \\
Desvio Padrão: & 0,236 & 0,245 & 0,269 & 0,258 & 0,246 & 0,233 \\
\hline
\end{tabular}

Comportamento parecido aconteceu com o NDVI, onde a maior e a menor média foi para os anos de 2010 e 2017, respectivamente. Conforme Alves et al., (2018), os índices de vegetação tendem a apresentar um comportamento semelhante e a variação a maior ou menor estariam associadas à estação chuvosa ou seca, uma vez que, a vegetação responde imediatamente à precipitação local.

Observou-se para os valores de mínimo de SAVI que o ano de 2008 apresentou o menor valor -0,471 e no ano de 2017 temos o menor valor de mínimo -0,168. Nos resultados de máximo, temos o maior valor de 0,748 para o ano de 2015 e o menor valor de 0,694 de máximo para o ano de 2017.

Por sua vez, o desvio padrão para o SAVI teve comportamento parecido com o NDVI, no qual ambos apresentaram altos valores de desvio. Isso pode ser explicado pela variabilidade de ambientes existentes na bacia do Rio Puruzinho. O maior valor de desvio padrão foi 0,269 para o ano de 2010 e o menor, 0,233, foi registrado no ano de 2017.

A distribuição espacial do SAVI na bacia do rio Puruzinho no período analisado é ilustrada na Figura 4. A apresentação dos valores do SAVI é feita por intervalos, separadas em cinco classes. O primeiro intervalo representa os valores de SAVI menores que zero; a segunda classe compreende o intervalo entre $0-0,3$; o intervalo entre 0,3-0,5 abrange classe seguinte; o intervalo de valores entre 0,5 - 0,6 é a quarta classe; e por fim, a última classe representa os valores maiores que 0,6 (LIMA et al., 2015).

Os valores de SAVI menores que zero representam ambientes com presença de água, assim 
como os valores compreendido entre 0 a 0,3 representam áreas com solo exposto. Leite et al., (2017), estudando a análise temporal dos índices de vegetação NDVI e SAVI na estação experimental de Itatinga, encontraram valor de SAVI de 0,24 para solo exposto, resultado semelhante ao encontrado por este trabalho.

Assim, valores de SAVI de 0,49 foram encontradas para vegetação ripária, caracterizada como vegetação rasteira, gramíneas ou pastagem. Alves et al., (2018) estimaram valores de SAVI variando entre 0,15 a 0,35, com valor médio de 0,27 em estudo na bacia hidrografia do rio Paraíba, observando que a variação no índice se dava de acordo com a transição da estação seca para a chuvosa, como consequência direta do estresse hídrico na vegetação.
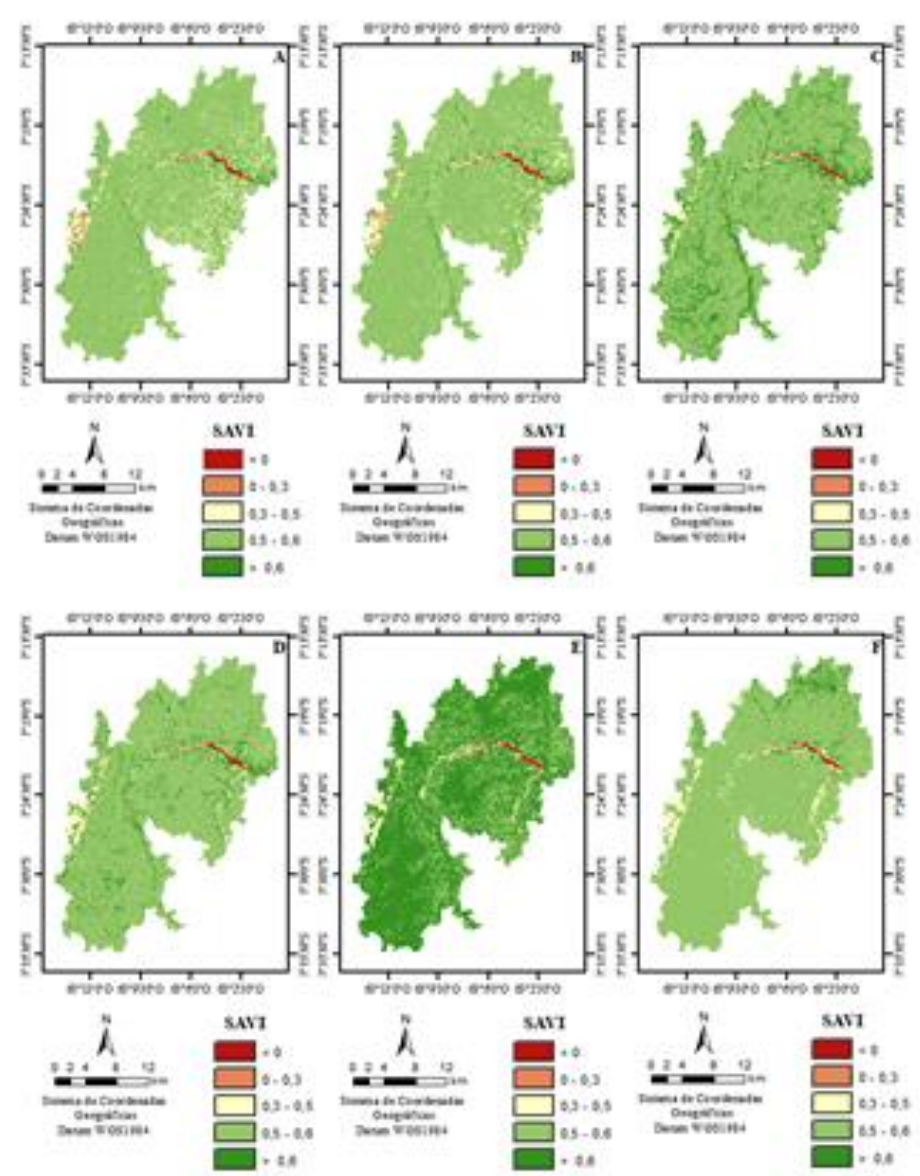

Figura 4 - Distribuição espacial do SAVI, para os anos de 2006 (A), 2008 (B), 2010 (C), 2011(D), 2015 (E) e 2017 (F), na bacia do Rio Puruzinho.

A distribuição espaço temporal do desvio padrão médio dos anos estudados para o SAVI, na bacia do rio Puruzinho é apresentada Figura 5. A representação da distribuição espaço temporal do desvio padrão médio do SAVI foi feita em cinco intervalos, atribuindo cores para a simbolização no mapa temático, onde a cor verde escuro representa os valores menores que 0,02 , entre $0,02-0,04$ representado pela cor verde claro, entre $0,04-0,06$ pela cor amarela, entre $0,06-0,08$ pela cor alaranjada e os valores maiores que 0,08 pela cor vermelha. 
Os maiores valores de desvio padrão do SAVI são representados pela cor vermelha, demostrando assim áreas onde é possível identificar áreas que estão mais degradadas, evidenciando a condição de solo exposto.

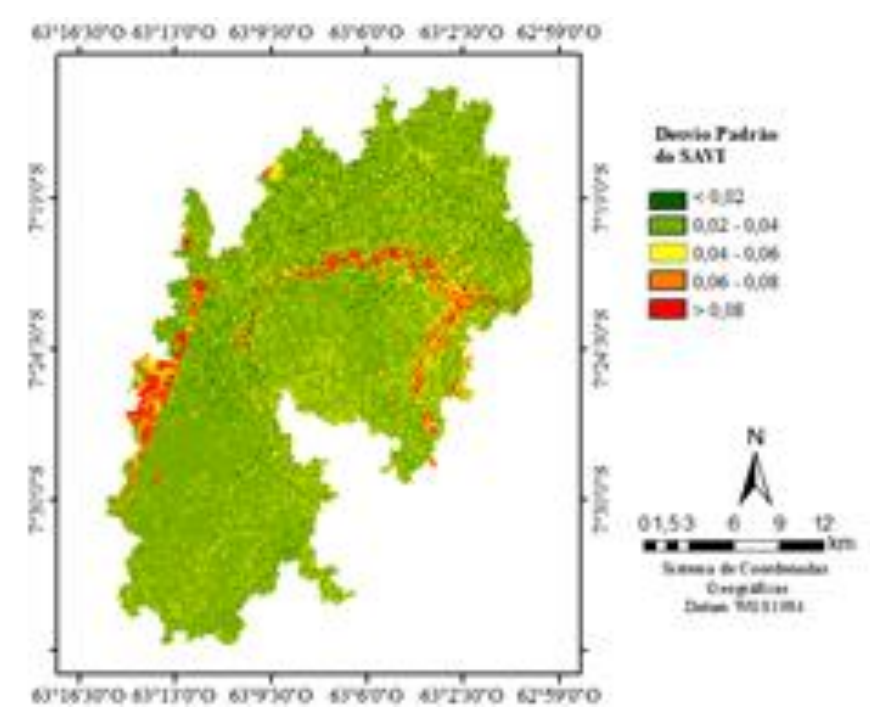

Figura 5 - Distribuição espaço temporal do desvio padrão médio para o SAVI, na bacia do rio Puruzinho.

Os resultados das análises do Índice de Área Foliar (IAF) entre os anos de 2006 e 2017 são apresentados na Tabela 7, com a maior média encontrada para o IAF referente ao ano de 2015, com valor de 2,414 e a menor foi para o ano de 2008, com valor de 0,841 .

Tabela 6: Resultados do IAF para a bacia do Rio Puruzinho.

\begin{tabular}{ccccccc}
\hline Estatística & $\mathbf{2 0 0 6}$ & $\mathbf{2 0 0 8}$ & $\mathbf{2 0 1 0}$ & $\mathbf{2 0 1 1}$ & $\mathbf{2 0 1 5}$ & $\mathbf{2 0 1 7}$ \\
\hline Mínimo: & $-0,511$ & $-0,677$ & $-0,572$ & $-0,590$ & $-0,416$ & $-0,375$ \\
Máximo: & 8,080 & 4,838 & 9,400 & 9,357 & 12,523 & 4,535 \\
Média: & 0,859 & 0,841 & 1,055 & 0,875 & 2,414 & 1,285 \\
Desvio Padrão: & 0,836 & 0,837 & 1,055 & 0,946 & 1,709 & 0,950 \\
\hline
\end{tabular}

No que se refere aos valores de mínimo para o IAF, temos o maior valor de mínimo -0,677 para o ano de 2008 e o menor valor de mínimo -0,375 para o ano de 2017. Para os resultados de máximo, temos para o ano de 2015, 12,523 como maior valor de máximo e para o ano de 2017, temos o menor valor de máximo sendo 4,535.

Os valores do desvio padrão do IAF obtiveram uma alta variação, alternando entre o maior de desvio padrão para a imagem do ano de 2015, com valor de 1,709, e o menor valor para a imagem do ano de 2006, com valor de 0,836 .

A distribuição espacial do IAF entre os anos de 2006 e 2017 são apresentados na Figura 6. ilustrando os valores em intervalos, divididas em cinco classes. A primeira classe é representa os valores menores que zero; a segunda, valores entre 0 - 1,0; a terceira, valores entre 1,0 - 1,5; a quarta, 
valores entre 1,5 - 2,0 e a última classe, representa valores maiores que 2 (BAPTISTA, 2020).

As áreas cujo IAF apresentou valores menores que zero representam áreas de rio e/ou lagos, enquanto as áreas com valores de IAF entre 0 - 1,0 simbolizam a ocorrência de solo exposto, ou áreas com altas características de degradação ambiental (SOUZA et al., 2016). Áreas com valores de IAF na ordem de 1,0 a 1,5 são áreas onde há predominância de vegetação menos densa ou gramíneas. Áreas com predominância de vegetação arbustiva são aquelas que apresentam valores de IAF entre 1,5 a 2,0 e as áreas com valores de IAF maior que 2,0 são aquelas com ocorrência de vegetação mais densa ou arbórea, resultados semelhantes foram encontrados por Silva et al., (2016).
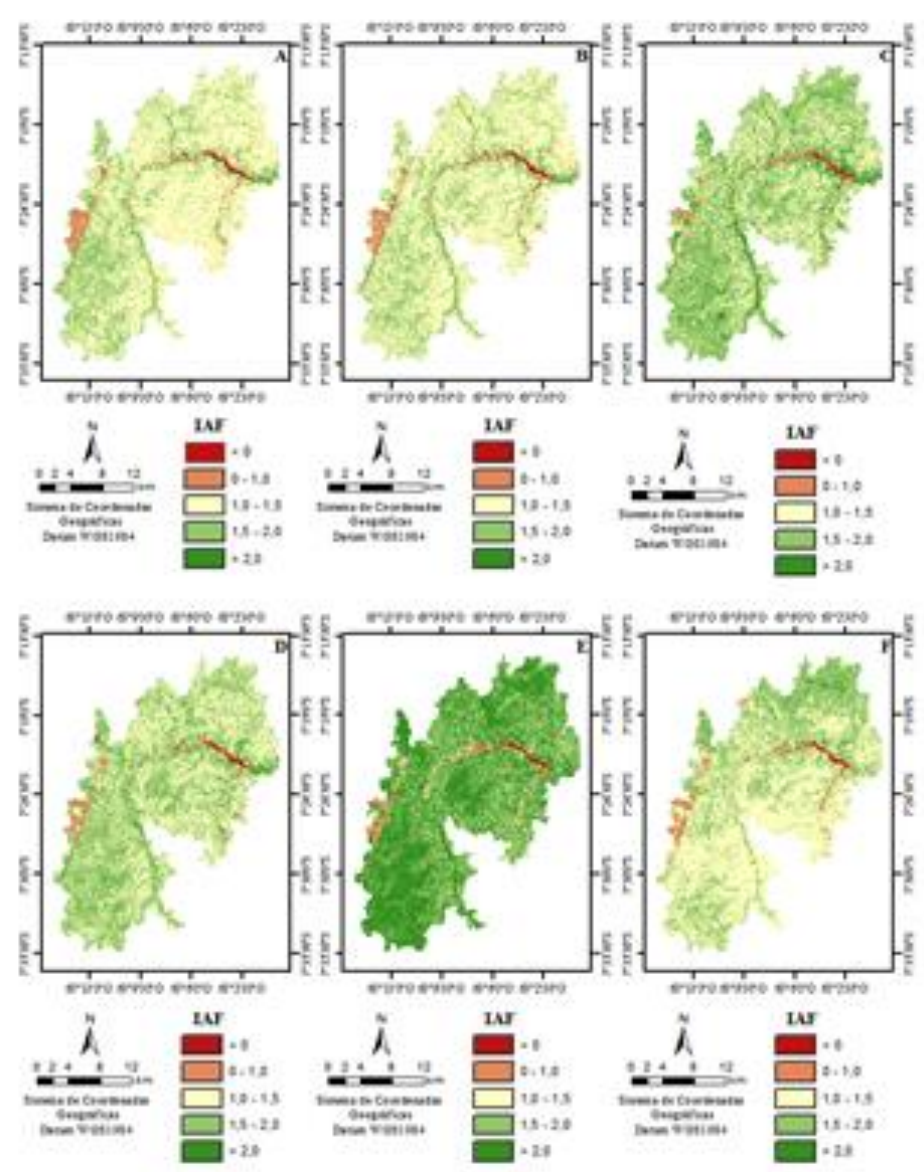

Figura 6 - Distribuição espacial do IAF, para os anos de 2006 (A), 2008 (B), 2010 (C), 2011 (D), 2015 (E) e 2017 (F), na bacia do Rio Puruzinho.

Todos os anos analisados na bacia demonstram uma predominância pela classe de IAF entre 1,0 a 1,5, evidenciando uma maior ocorrência de vegetação rasteira/arbustiva, ou seja, uma vegetação menos densa, exceto o ano de 2015, onde foi evidenciado uma maior densidade na vegetação para aquele ano. 


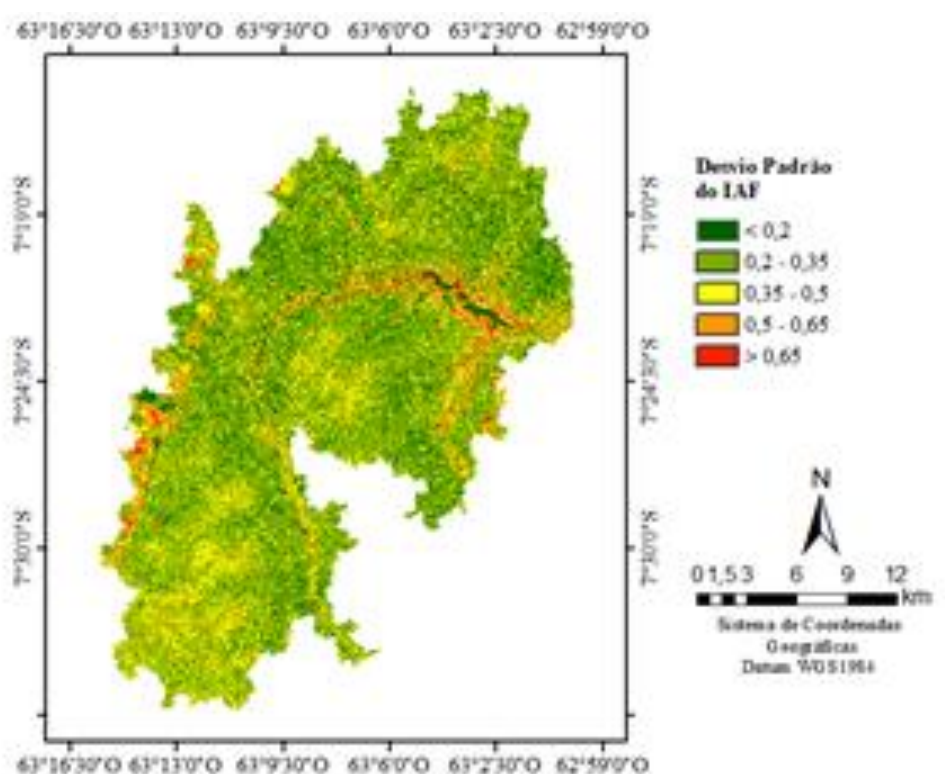

Figura 7 - Distribuição espaço temporal do desvio padrão médio para o IAF, na bacia do rio Puruzinho.

A distribuição espaço temporal do desvio padrão médio dos anos estudados para o IAF, na bacia do rio Puruzinho é apresentada Figura 7. A representação da distribuição espaço temporal do desvio padrão médio do IAF foi feita em cinco intervalos, cujo primeiro intervalo representa os valores maiores que 0,2; o segundo intervalo compreende os valores entre 0,2 - 0,35; o terceiro, valores entre $0,35-0,5$; o quarto, valores entre $0,5-0,65$; o quinto intervalo possui valores maiores que 0,65. Com relação ao desvio do IAF, observa-se pelo mapa que não ouve grandes alterações, exceto em alguns pontos próximos a rodovia e nas adjacentes dos lagos.

Os resultados de albedo estimados para o período analisado na bacia do rio Puruzinho são apresentados na Tabela 8.

Tabela 7: Resultados de albedo estimados para a bacia do Rio Puruzinho no período analisado.

\begin{tabular}{ccccccc}
\hline Estatística & $\mathbf{2 0 0 6}$ & $\mathbf{2 0 0 8}$ & $\mathbf{2 0 1 0}$ & $\mathbf{2 0 1 1}$ & $\mathbf{2 0 1 5}$ & $\mathbf{2 0 1 7}$ \\
\hline Mínimo: & 0,048 & 0,043 & 0,031 & 0,039 & 0,036 & 0,088 \\
Máximo: & 0,314 & 0,291 & 0,295 & 0,287 & 0,277 & 0,283 \\
Média: & 0,160 & 0,150 & 0,137 & 0,145 & 0,150 & 0,180 \\
Desvio Padrão: & 0,067 & 0,063 & 0,063 & 0,060 & 0,065 & 0,053 \\
\hline
\end{tabular}

Em relação à média, o maior valor de albedo apurado foi 0,180 , observado para o ano de 2017 e o menor foi 0,137 para o ano de 2010. Sobre os valores máximos de albedo, o maior valor encontrado corresponde ao ano de 2006, na ordem de 0,314 e o menor valor foi observado para o ano de 2015, estimado em 0,277. Para os resultados de mínimo, o maior valor apurado corresponde ao ano de 2017, computado em 0,088 e o menor valor foi para o ano de 2010, estimado em 0,031. Em relação ao desvio padrão, o maior valor corresponde ao ano de 2006, onde foi apurado 0,067 e o menor valor corresponde ao ano de 2017 , com valor de 0,053 . 
Gomes et al., (2017), estudando temperatura da superfície e albedo região de Ilha Solteira nos anos de 2010 e 2011, registraram resultados semelhantes aos estimados neste estudo, com média para o albedo no valor de 0,015, mínimo entre 0,020 e 0,037 e o desvio padrão de 0,032 e 0,034, ressaltando a associação dos valores de albedo com as características da superfície analisadas e os fatores climáticos para os dias observados. Segundo Faria et al., (2018), o albedo apresenta variações temporais e espaciais, respondendo conforme as propriedades das superfícies, como a umidade por exemplo.

Um estudo conduzido por Padovanni et al., (2018) na Bacia do Rio Una, os autores estimaram valores entre 0,121 a 0,196 , onde os menores valores são condizentes com superfícies vegetadas ou úmidas, enquanto áreas com solo exposto apresentaram os maiores valores de albedo. Nesse sentido, Faria et al., (2018) destacam a importância da mensuração do albedo em áreas com alterações em sua cobertura ou uso do solo, pois permite entender os impactos humanos sobre o meio ambiente.

Áreas de floresta nativa registram menores valores de albedo e isso decorre da maior absorção da radiação, mesmo quando comparadas com áreas vegetadas, porém de menor porte, à exemplos de cultivos (BORELLA et al., 2018). Tal constatação vai ao encontro do afirmado por Faria et al., (2018), cuja variação de albedo em superfícies vegetadas está intrinsicamente ligada aos estágios de desenvolvimento vegetal como também, às espécies analisadas. Alves et al., (2018) destacam que superfícies com solos possuem alta refletividade, resultando em grandes perdas de energia. A distribuição espacial do albedo, entre os anos de 2006 e 2017 é apresentada Figura 8. 

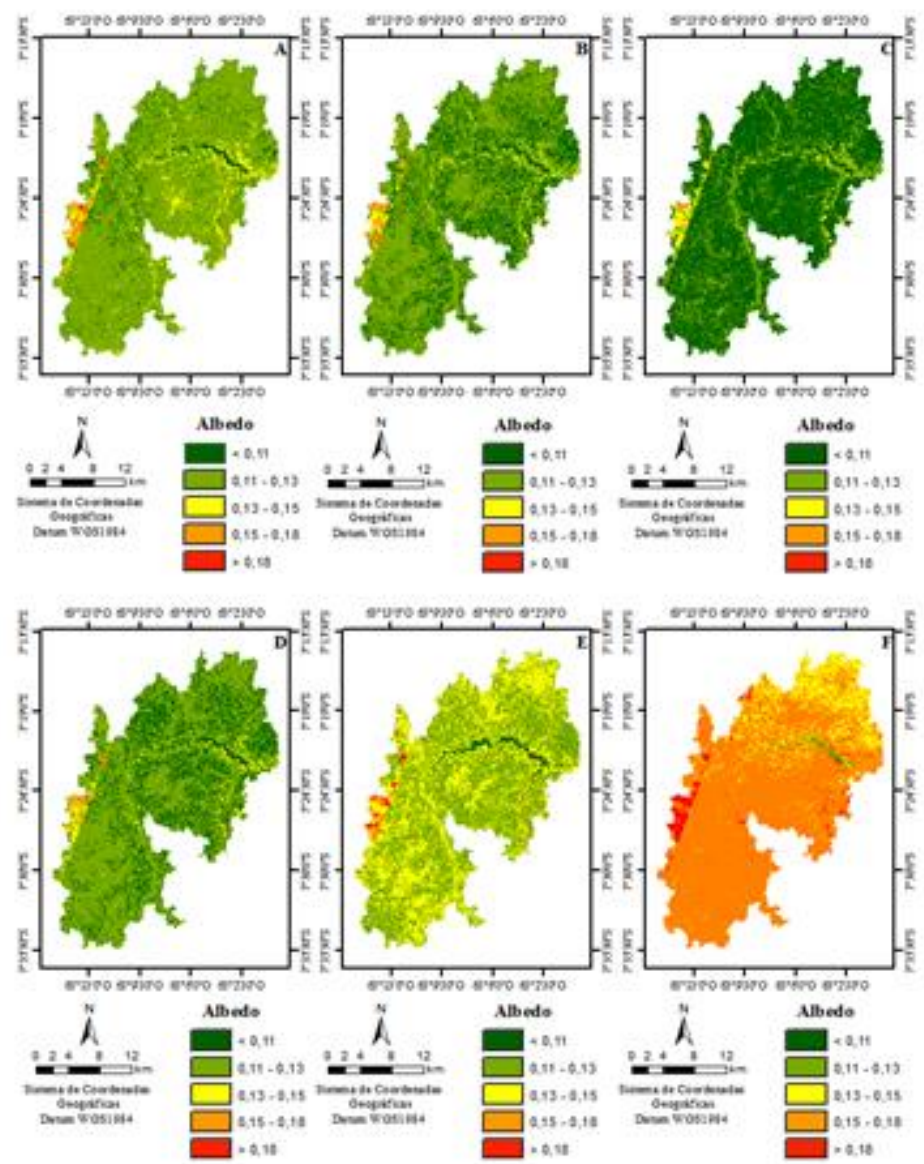

Figura 6 - Distribuição espacial do albedo, para os anos de 2006 (A), 2008 (B), 2010 (C), 2011(D), 2015 (E) e 2017 (F), na bacia do Rio Puruzinho.

A ilustração da variação espacial é feita pela atribuição de cores a intervalos de ocorrência dos valores de albedo, estes divididos em cinco. O primeiro intervalo é representado pela cor verde escuro, e ilustra no mapa temático os valores de albedo menores que 0,11. O intervalo entre 0,110,13 é representado pela cor verde claro, para o intervalo entre $0,13-0,15$ a cor utilizada foi a amarela, o intervalo entre 0,15 - 0,18 é simbolizado pela cor alaranjada e os valores de albedo maiores que 0,18 são representados pela cor vermelha.

Predominam na bacia do rio Puruzinho, para os anos de 2006, 2008, 2010 e 2011, valores até 0,13 para o albedo; há ainda áreas com valores de albedo, até 0,11. Lopes e Valeriano, (2007) encontraram valores entre 0,02 e 0,10 de albedo para represas em Furnas, no Vale do Rio Paraíba do Sul. Estes valores corroboram com os resultados encontrados por Fausto et al., (2016), os quais encontraram valores de 0,05 de albedo para superfícies de corpos d'agua e com Silva et al., (2005) que obtiveram valores de 0,08 e 0,09 de albedo em lagos.

Nas áreas vegetadas, temos valores semelhantes aos encontrados por Querino et al., (2006), que mensurou valores similares para floresta, na ordem de 0,13 , estudando o albedo na região Amazônica.

A distribuição espaço temporal do desvio padrão médio dos anos estudados para o albedo, 
na bacia do rio Puruzinho é apresentada Figura 9. A distribuição do desvio padrão médio foi representada no mapa temático atribuindo cores aos intervalos de ocorrência, estes divididos em cinco.

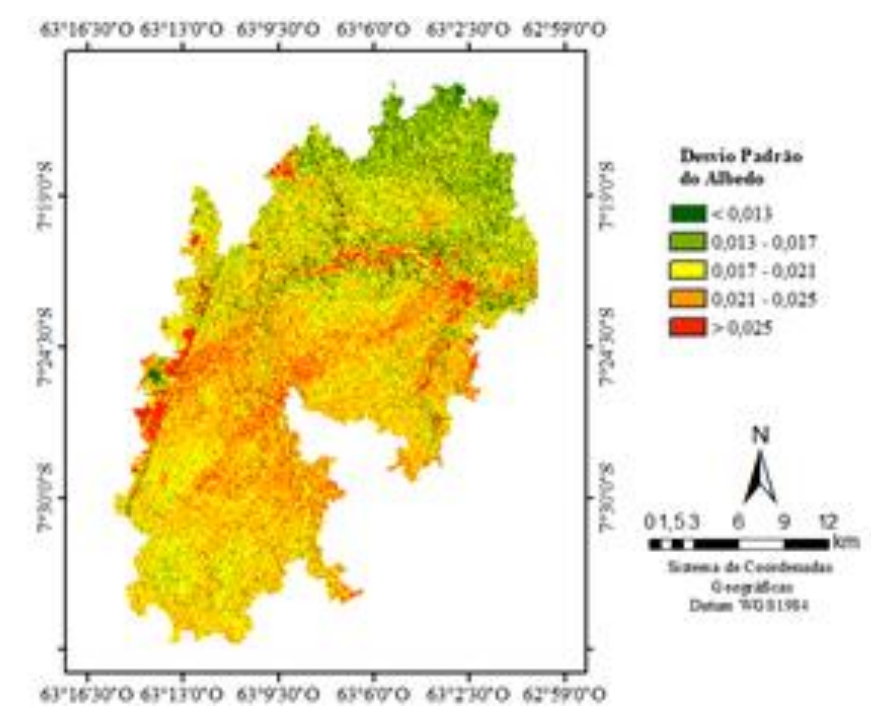

Figura 7 - Distribuição espaço temporal do desvio padrão médio para o albedo, na bacia do rio Puruzinho.

A cor verde-escura representa os valores menores que 0,013 , entre $0,013-0,017$ pela cor verde claro, entre $0,017-0,021$ pela cor amarela, entre 0,021-0,025 pela cor alaranjada, os valores maiores que 0,025 são representados pela cor vermelha. As maiores variações de albedo são representadas pela cor vermelha, assim como para os indicies biofísicos, o albedo apresentou maiores variações nas mesmas regiões que os índices, Pereira et al., (2007), dizem que a vegetação densa e sua distribuição, influenciam no albedo.

Os resultados da temperatura da superfície estimados entre os anos de 2006 e 2017 são apresentados na Tabela 9.

Tabela 8: Temperatura da superfície em graus Celsius $\left({ }^{\circ} \mathrm{C}\right)$ para a bacia do Rio Puruzinho.

\begin{tabular}{ccccccc}
\hline \multirow{2}{*}{ Estatística } & $\mathbf{2 0 0 6}$ & $\mathbf{2 0 0 8}$ & $\mathbf{2 0 1 0}$ & $\mathbf{2 0 1 1}$ & $\mathbf{2 0 1 5}$ & $\mathbf{2 0 1 7}$ \\
\hline Mínimo: & 20,94 & 16,08 & 18,25 & 20,50 & 25,20 & 20,34 \\
Máximo: & 32,78 & 28,16 & 28,90 & 37,90 & 34,07 & 35,16 \\
Média: & 26,43 & 21,75 & 22,27 & 25,59 & 29,54 & 26,17 \\
Desvio Padrão: & 2,56 & 3,06 & 2,08 & 2,88 & 2,51 & 3,55 \\
\hline
\end{tabular}

O valor médio mais alto registrado foi o valor de $29,54^{\circ} \mathrm{C}$ no ano de 2015 e o menor foi o valor de $21,75^{\circ} \mathrm{C}$ para o ano de 2008 . Em relação à máxima, o valor mais alto para o período analisado foi estimado para o ano de 2011 , com temperatura da superfície de $37,90{ }^{\circ} \mathrm{C}$ e o menor valor foi no ano de 2008 com temperatura da superfície por volta de $28,16^{\circ} \mathrm{C}$. Em relação à mínima, o valor mais alto observado foi no ano de 2015 , com temperatura de superfície na ordem de $25,20{ }^{\circ} \mathrm{C}$ e o menor 
valor foi registrado no ano de 2008, com temperatura da superfície volta de $16,08{ }^{\circ} \mathrm{C}$. Com relação aos resultados do desvio padrão da temperatura da superfície, o maior desvio calculado ocorreu no ano de 2017, com valor de 3,55 e o menor, deu-se no ano de 2010 com valor de 2,08. Tais valores são semelhantes aos encontrados por Gomes et al., (2017), onde estes observaram temperatura mínima valor de $18^{\circ} \mathrm{C}$, máxima de $34^{\circ} \mathrm{C}$, média de $24,5^{\circ} \mathrm{C}$ e desvio padrão de $2,2^{\circ} \mathrm{C}$.

A temperatura da superfície está relacionada com a característica do ambiente na superfície, áreas antropizadas, desmatadas ou com baixa vegetação ocasionam áreas com temperaturas mais altas, temperaturas de $23,7^{\circ} \mathrm{C}$ para áreas desmatadas, $25,1^{\circ} \mathrm{C}$ para campos naturais, $28,7^{\circ} \mathrm{C}$ para áreas urbanas e $20,8^{\circ} \mathrm{C}$ para ares de florestas densas foram observados por Tartari et al., (2015). De acordo com Padovanni et al., (2018), a temperatura de superfície relaciona-se com o tipo de cobertura e uso do solo, onde áreas de cultivos temporários ou urbanizadas tendem a apresentar temperatura de superfície maiores que áreas florestadas ou com silvicultura instalada.

A distribuição espacial dos resultados para temperatura da superfície entre os anos de 2006 e 2017 são apresentados apresentadas Figura 10. Para as temperaturas menores que $21{ }^{\circ} \mathrm{C}$, a cor utilizada no mapa temático foi a cor verde escura; entre $21{ }^{\circ} \mathrm{C}-23{ }^{\circ} \mathrm{C}$ representada pela cor verde claro; o intervalo de $23{ }^{\circ} \mathrm{C}-25^{\circ} \mathrm{C}$ é representado na cor amarela; o intervalo de $25{ }^{\circ} \mathrm{C}-27{ }^{\circ} \mathrm{C}$ foi utilizada a cor alaranjada; para as temperaturas maiores que $27^{\circ} \mathrm{C}$ utilizou-se a cor vermelha.

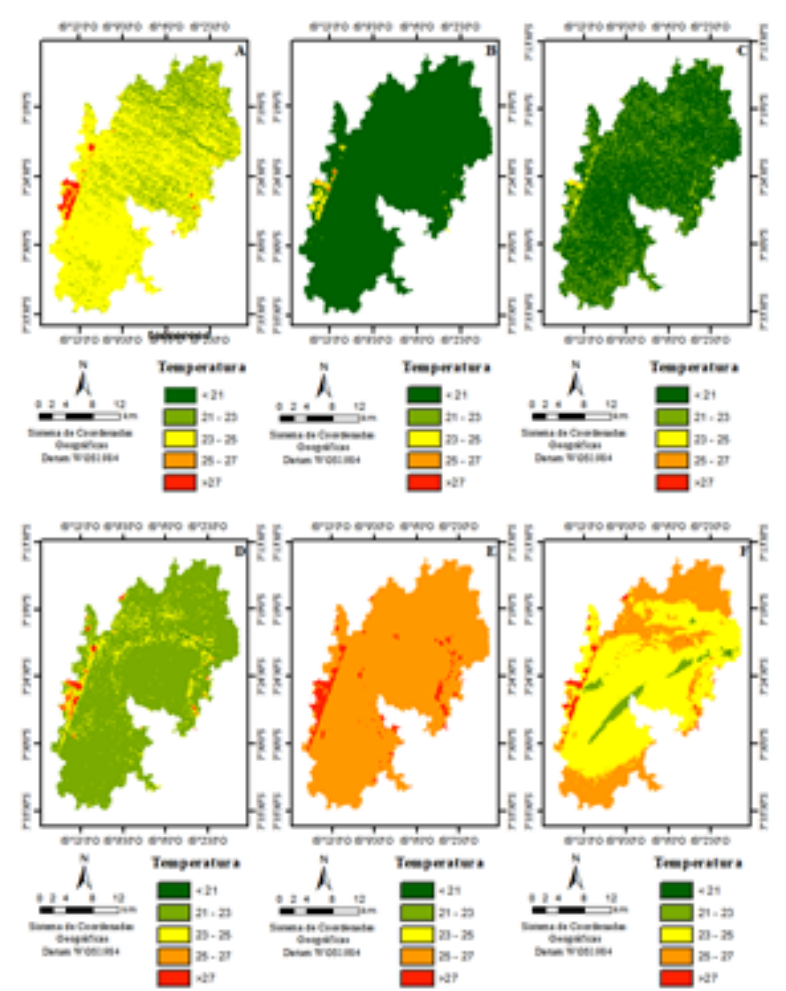

Figura 8 - Distribuição espacial da temperatura da superfície, para os anos de 2006 (A), 2008 (B), 2010 (C), 2011(D), 2015(E) e 2017 (F), na bacia do Rio Puruzinho.

A temperatura da superfície estimada nos de 2008 (B) e 2010 (C) variaram entre $21^{\circ} \mathrm{C}$ e $23^{\circ} \mathrm{C}$. Os anos de 2015 (E) e 2017 (F) as temperaturas oscilaram entre $23^{\circ} \mathrm{C}$ e $27^{\circ} \mathrm{C}$. Pavão et al., 
(2015), encontraram altos valores para temperatura da superfície no entorno da cidade de HumaitáAM, em áreas modificadas pela ação antrópica.

Alterações no uso e cobertura do solo causam diminuição ou aumento da temperatura de superfície, visto que estas modificações podem deixar ou não o solo exposto (MORAES et al., 2018). Da análise dos valores da temperatura de superfície encontrados, percebe-se que o ano de 2015 apresentou valores de temperatura da superfície mais elevados. De acordo com Padovanni et al., (2018), isso também poderia estar relacionado ao comportamento climático anômalo no ano de 2015, no qual houve o registro do fenômeno El Niño.

A distribuição espaço temporal do desvio padrão médio da temperatura da superfície na bacia do rio Puruzinho é apresentada Figura 11. Para a representação, os valores foram divididos em cinco intervalos simbolizados por cores.

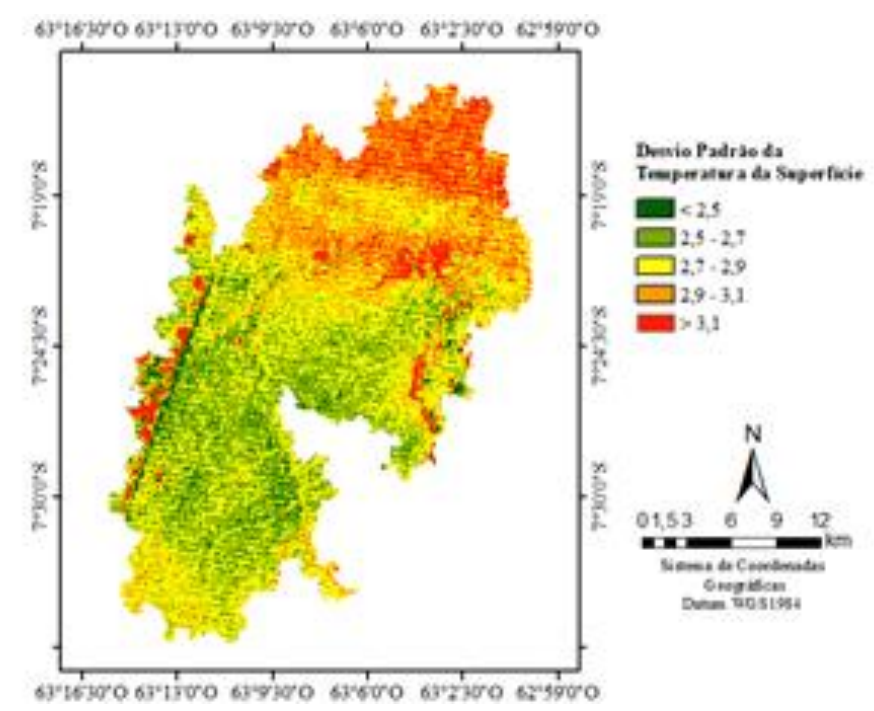

Figura 11 - Distribuição espaço temporal do desvio padrão médio para a temperatura da superfície, na bacia do rio Puruzinho.

Há uma grande variação da temperatura ao longo dos anos estudados, as menores variações são simbolizadas pela cor verde, que ocorrem em minoria no mapa temático. As maiores modificações do desvio padrão da temperatura da superfície são ilustradas no mapa pelas cores alaranjada e vermelha.

\section{CONCLUSÃO}

O albedo e a temperatura foram maiores e apresentaram maiores variações em áreas sem ou com pouca vegetação, onde houve retirada da vegetação primária. Os índices biofísicos exibiram padrão inverso entre as áreas de floresta densa e áreas antropizadas. Demonstrando os maiores valores de NDVI para floresta e os menores para áreas de solo exposto ou vegetação rasteira. 
A utilização dos índices biofísicos, combinados com técnicas de sensoriamento remoto e geoprocessamento, mostraram-se ferramenta imprescindível no monitoramento e detecção de áreas com transformações ambientais com uso de imagens de satélite para extensas áreas.

\section{REFERÊNCIAS}

ACCIOLY, L. J.; PACHECO, A.; COSTA, T. C. C.; LOPES, O. F.; OLIVEIRA, M. A. J. Relações empíricas entre a estrutura da vegetação e dados do sensor TM/Landsat. Revista Brasileira de Engenharia Agrícola e Ambiental, v. 6, n. 3, p. 492-498, 2002.

ALLEN, R. G.; TASUMI, M.; TREZZA, R. SEBAL. Surface Energy Balance Algorithms for Land. Advanced Training and User's Manual - Idaho Implementation, version 1.0. 2002. 97p.

ALVARES, C. A.; STAPE, J. L.; SENTELHAS, P. C.; GOLÇALVES, J. L. M.; SPAROVEK, G. Köppen's climate classification map for Brazil. Meteorologische Zeitschrift, v. 22, n. 6, p. 711-718, 2014.

ALVES, T. L. B.; AZEVEDO, P. V.; SANTOS, C. A. C.; SANTOS, F. A. C. Evolução espaçotemporal do albedo e da cobertura vegetal da superfície na bacia hidrográfica do alto curso do rio Paraíba. Geosul, v. 33, n. 66, p. 147-171, 2018.

BOEGH, E.; SOEGAARD, H.; THOMSEN, A. Evaluating evapotranspiration rates and surface conditions using Landsat TM to estimateatmospheric resistance and surface resistance. Remote Sensing of Environment, v. 79, p. 329-343, 2002.

BAPTISTA, M. Análise temporal de NDVI sobre a cobertura vegetal da Área de Proteção Ambiental (APA) Costa Brava em Balneário Camboriú (SC). Metodologias e Aprendizado, v. 2, p. 197-202, 2020.

BORELLA, D. R.; SIQUEIRA, F. R. P. S.; FARIA, T. O.; BIUDES, S.; MACHADO, N. G. Efeito da conversão da vegetação nativa em áreas agrícolas sobre variáveis biofísicas na região de transição Cerrado-Amazônia. Revista Ciência e Natura, v. 40, n. 12, p. 1-12, 2018.

BORGES, V. P.; OLIVEIRA, A. S.; SILVA, B. B. Mapeamento e quantificação de parâmetros biofísicos radiação líquida em área de algodoeiro irrigado. Ciênc. Agrotec., Lavras, v. 34, n. 2, p. 485-193, 2010.

CHANDER, G.; MARKHAM, B. Revised Landsat-5 TM Radiometric Calibration Procedures and Postcalibration Dynamic Ranges. IEEE Transactions on Geoscience and Remote Sensing, v, 41, n. 11, p. 2674-2677, 2003.

FARIA, T. O.; RODRIGUES, T. R.; CURADO, L. F. A.; GAIO, D. C.; NOGUEIRA, J. S. Surface albedo in different land-use and cover types in Amazon forest region. Ambiente \& Agua - An Interdisciplinary Journal of Applied Science, v. 13, n. 2, p. 1-13, 2018.

FARR, T. G.; ROSEN, P. A.; CARO, E.; CRIPPEN, R.; DUREN, R.; HENSLEY, S.; KOBRICK, M.; PALlER, M.; RODRIGUEZ, E.; ROTH, L.; SEAL, D.; SHAFFER, S.; SHIMADA, J.; UMLAND, J.; WERNER, M.; OSKIN, M.; BURBANK, D.; ALSDORF, D. The Shuttle Radar Topography Mission. Reviews of Geophysics, v. 45, 2007. 
FEARNSIDE, P. M. Desmatamento na Amazônia: dinâmica, impactos e controle. Acta Amazônica, v. 36, n. 3, p. 395-400, 2006.

FREIRES, E. V.; DA SILVA NETO, C. Â.; CUNHA, D. S. R.; DUARTE, C. R.; VERÍSSIMO; C. U. V., GOMES, D. D. M. Comparação de Imagens OLI/Landsat-8 e MSI/Sentinel-2 no Mapeamento de Cobertura e Uso da Terra no Maciço de Uruburetama, Ceará. Anuário do Instituto de Geociências, v. 42, n. 4, p. 427-442, 2020.

GOMES, H. B.; CAVALCANTE, L. B.; SILVA JUNIOR, R. S. D.; SANTOS, M. N. D. Temperatura da Superfície e Albedo na Região de Ilha Solteira, São Paulo. Mercator, Fortaleza, v. 16, n. 8, p. 116, 2017.

HUETE, A. R.; WARRICK, A. W. Assessment of Vegetation and Soil Water Regimes in Partial Canopies with Optical Remotely Sensed Data. Remote Sensing of Environment., v. 32, p. 155-167, 1990.

IQBAL. M. An Introduction to Solar Radiation. Library of Congress Cataloging in Publication data, Academic Press Canadian. 1983. 390p.

JÚNIOR, F. R. F.; SOUZA, R. B. B.; CEDRO, T. A. P.; VALÉRIO, R. A.; DIAS, E. S.; BRANDÃO, P. R. B.; SANTOS, J. Y. G. Dinâmicas territoriais e desafios ambientais na cidade de Barra (Bahia, Brasil). Revista Ibero-Americana de Ciências Ambientais, v. 11, n. 7, p. 474-483, 2020.

LEITE, A. C. S.; BEZERRA, U. A.; OLIVEIRA, L. M. M. Comportamento do Albedo e NDVI no Núcleo de Desertificação de Gilbués - Piauí (Brasil), usando imagens do Satélite Landsat. Revista Brasileira de Meio Ambiente, v. 7, n. 2, p. 19-28, 2019.

LEITE, A. P.; SANTOS, G. R.; SANTOS, J. É. O. Análise temporal dos índices de vegetação NDVI e SAVI na Estação Experimental de Itatinga utilizando imagens Landsat 8. Revista Brasileira de Energias Renováveis, v. 6, n. 4, p. 606-623, 2017.

LIMA, A. S.; NASCIMENTO, D. T.; OLIVEIRA, J. H.; SOUZA, L. V.; BERTOLINI, G. R. F. Analysis space-time coverage of vegetable, caetés county-pe, through of NDVI image data. Revista Eletrônica em Gestão, Educação e Tecnologia Ambiental, v. 19, n. 2, p. 775-793, 2015.

LOPES, P.; VALERIANO, D. Validação do albedo da superfície terrestre obtido dos dados do sensor MODIS em regiões montanhosas. In: SIMPÓSIO BRASILEIRO SOBRE SILÍCIO NA AGRICULTURA. 13., 2007, Florianópolis. Anais... Florianópolis. 2007. p. 2805-2812.

MACEDO, R. C.; ALMEIDA, C. M.; SANTOS, J. R. Valoração Ambiental E Geotecnologias: Integração Entre Ciências Sociais E Geociências. Revista Brasileira de Cartografia, v. 68, n. 2, p. 1-12, 2016.

MARKHAM, B. L.; BARKER, L. L. Thematic mapper bandpass solar exo atmospherical irradiances. International Journal of Remote Sensing, v. 8, n. 3 p. 517-523, 1987.

MORAES, E. C. Fundamentos de sensoriamento remoto. São José dos Campos: INPE, 2002. 23p.

MORAES, V. H.; GIONGO, P. R.; CAVAlCANTE, T. J.; GIONGO, A. M. M.; ARANTES, B. H. T.; COSTA, E. M.; VENTURA, M. V. A. Use of Remote Sensing in the Evaluation of the Behavior of Biophysical Variables in the Cerrado Biome. Australian Journal of Basic and Applied Sciences, v. 12, n. 12, p. 36-40, 2018. 
PADOVANNI, N. G.; LOPES, E. R.; SOUZA, J. C.; MORAIS, M. C. M.; LOURENÇO, R. W. Análise Espacial da Temperatura e Albedo de Superfície na Bacia Hidrográfica do rio Una Ibiúna/São Paulo, a partir de imagens MODIS. Revista Brasileira de Geografia Física, v. 11, n. 5, p. 1832-1845, 2018.

PAIVA, C. M.; DA SILVA GONÇALVES DE JESUS, A.; BORGES FRANÇA, G.; TEMPONI OLIVEIRA, L. M. Análise dos Efeitos do Déficit Hídrico na Resposta Temporal do Índice de Vegetação por Diferença Normalizada (NDVI) no Estado do Amazonas. Ciência e Natura, v. 38, n. 2, p. 1064-1076, 2016.

PAVÃO, V. M.; QUERINO, C.; BENEDITTI, C.; PAVÃO, L. L.; QUERINO, J.; MACHADO, N. G.; BIUDES, M. S. Temperatura e albedo da superfície por imagens TM Landsat 5 em diferentes usos do solo no sudoeste da Amazônia brasileira. Revista Brasileira de Climatologia, v. 16, p. 169$183,2015$.

PEREIRA, G.; MORAES, E. C.; ARAI, E.; OLIVEIRA, L. G. L. Estudo preliminar da estimativa da reflectância e albedo de microssistemas pantaneiros a partir de imagens de satélite. Revista Brasileira de Cartografia, v. 59, n. 1, p. 55-61, 2007.

QUERINO, C. A. S.; MOURA, M. A. L.; LYRA, R. D. F.; MARIANO, G. L. Avaliação e comparação de radiação solar global e albedo com ângulo zenital na região Amazônica. Revista Brasileira de Meteorologia, v. 21, n. 3a, p. 42-49, 2006.

QUESADA, H. B.; REDONDO, G.; VERNASQUI, L. G.; MAGNONI, P. H. J.; ARANTES, E. J. Análise da vegetação ripária em bacia hidrográfica utilizando Índice de Vegetação Normalizada (NDVI) no município de Maringá-PR. Geo UERJ, Rio de Janeiro, v. 31, p. 439-455, 2017.

ROSSONI, R. A.; MORAES, M. L. Agropecuária e desmatamento na Amazônia legal brasileira: uma análise espacial entre 2007 e 2017. Geografia em Questão, v. 13, n. 3, p. 1-14, 2017.

SANTOS, J. E. O.; NICOLETE, D. A. P.; FILGUEIRAS, R.; LEDA, V. C.; ZIMBACK, C. R. L. Imagens do Landsat-8 no mapeamento de superfícies em área irrigada. IRRIGA, v. 1, n. 2, p. 1-30, 2018.

SILVA, B. B.; LOPES, G. M.; AZEVEDO, P. V. Balanço de radiação em áreas irrigadas utilizando imagens Landsat 5-TM. Revista Brasileira de Meteorologia, v. 20, n. 2, p. 243-252, 2005.

SILVA, J. S.; DA SILVA, R. M.; SILVA, A. M. Mudanças do Uso e Ocupação do Solo e Degradação Eco-Ambiental Usando Imagens Orbitais: O Estudo de Caso da Bacia do Rio Bacanga, São Luís (MA) (Land Use/Cover Change and Environmental Degradation Based on Orbital Images: A Case Study of Bacanga River). Revista Brasileira de Geografia Física, v. 9, n. 1, p. 265-279, 2016.

SOUZA, J. F. D.; SILVA, R. M.; SILVA, A. M. Influência do uso e ocupação do solo na temperatura da superfície: o estudo de caso de João Pessoa-PB. Ambiente Construído, v. 16, n. 1, p. 21-37, 2016.

SOUZA FILHO, P. W. M.; PARADELLA, W. R.; SOUZA JR., C.; VALERIANO, D. M.; MIRANDA, F. P. Sensoriamento Remoto e Recursos Naturais da Amazônia. Revista Ciência e Cultura, v. 58, n. 3, p. 37-41, 2006.

TARTARI, R.; GOMES MACHADO, N.; RODRIGUES DOS ANJOS, M.; DA CUNHA, J. M.; RALF DE MUSIS, C.; DE SOUZA NOGUEIRA, J.; SACARDI BIUDES, M. Análise de índices 
biofísicos a partir de imagens TM Landsat 5 em paisagem heterogênea no Sudoeste da Amazônia. Ambiente \& Água-An Interdisciplinary Journal of Applied Science, v. 10, n. 4, p. 943-953, 2015.

Trabalho enviado em 09/11/2020

Trabalho aceito em 15/04/21 